DOI 10.37882/2223-2974.2021.03.12

\title{
ПОЛНОМОЧИЯ ФНС РОССИИ ПО ПРОВЕРКЕ ДОСТОВЕРНОСТИ СВЕДЕНИЙ ПРИ РЕГИСТРАЦИИ ЮРИДИЧЕСКОГО ЛИЦА
}

\section{POWERS OF THE FEDERAL TAX SERVICE OF RUSSIA TO VERIFY THE ACCURACY OF INFORMATION WHEN REGISTERING A LEGAL ENTITY}

P. Kuznecov

Summary: This paper has summarized some discusses some legal problems related to the scope of the registration authority of the Federal Tax Service of Russia to verify the accuracy of information about the address of a legal entity, analyzes the criteria used by judicial practice in resolving disputes about refusals to register legal entities due to the unreliability of the address. The problems of theory and practice related to the definition of the content of fictitious bankruptcy as an administrative offense are analyzed.

Object. To assess some problematic issues related to the practical implementation of the powers of the registering authority to verify the accuracy of information about the address of a legal entity and the prospects for regulatory regulation of this activity.

Methods: systematic analysis, comparison and generalization.

Findings: proposals for improving the regulation of the implementation of the above powers: normative consolidation treatments match making (any) actual addresses in the FIAS in cases purely technical in nature, with no claim to legal entity about passing the registration and other procedures; development of methodological recommendations containing a clear algorithm of actions to verify the accuracy of information when registering a legal entity based on the practice of appealing decisions to refuse registration in the Federal Tax Service and in court.

Conclusions. The author concludes that the regulatory provisions governing the activities on registration of legal entities in terms of validation of information need to be clarified and corrected at the legislative level and in the framework of departmental regulations.

Keywords: registration of legal entities, powers of the Federal Tax Service of Russia, reliability of information about the address of the legal entity.

\section{Введение}

оиск оптимальной модели регулирования процедуры регистрации факта создания юридических лиц, начавшийся с момента перехода российского государства к капиталистической формации в 90-е годы XX века продолжается и сейчас. Традиционно считается, что ценность государственной регистрации компаний в доступности достоверной информации о юридическом лице, необходимой для защиты интересов третьих лиц, контактирующих с компанией и обеспечения стабиль-
Кузнецов Павел Александрович

аспирант, Северо-Западный институт управления Российской Академии народного хозяйства и государственной службы при Президенте РФ, г. Санкт-Петербург

tvinco@mail.ru

Аннотация: В статье рассматриваются некоторые правовые проблемы, связанные с объемом регистрационных полномочий ФНС России по проверке достоверности сведений 06 адресе юридического лица, анализируется критерии, используемые судебной практикой при разрешении споров об отказах в регистрации юридических лиц в связи с недостоверностью адреса. Цель: Оценить некоторые проблемные моменты, связанные с практической реализацией полномочий регистрирующего органа по проверке достоверности сведений 06 адресе юридического лица и перспективы нормативного упорядочения данной деятельности. Методы: систематический анализ, сравнение и обобщение. Результаты: Внесены предложения по совершенствованию регулирования реализации вышеуказанных полномочий: нормативное закрепление процедуры установления соответствий (наличия) фактического адреса и адреса в ФИАС в случаях, носящий чисто технический характер, без предъявления требований к юридическому лицу о прохождении регистрационных и иных процедур; разработка методических рекомендаций, содержащих чёткий алгоритм действий по проверке достоверности сведений при регистрации юридического лица на основе практики обжалования решений об отказе в регистрации в ФНС и судебном порядке. Выводы: Автор приходит к выводу, что нормативные положения, регламентирующие деятельность ФНС по регистрации юридических лиц в части проверки достоверности сведений, нуждаются в уточнении и корректировке как на законодательном уровне, так и в рамках ведомственных нормативных документов.

Ключевые слова: регистрация юридических лиц, полномочия ФНС России, достоверность сведений $0 б$ адресе юридического лица.

ности гражданского оборота [1, с. 72]. Соответственно регистрационная процедура должна содержать минимально необходимые фильтры, отсеивающие недобросовестных субъектов экономических отношений, защищая тем самым, как публичный интерес государства по эффективному сбору налогов, так и частные интересы бизнеса.

Статья 54 ГК РФ содержит требование об указании адреса юридического лица, в едином государственном реестре юридических лиц (ЕГРЮЛ). Обеспечение макси- 
мальной достоверности сведений реестра последовательно указывается как стратегическая цель ФНС в нормативных документах с 2016 года [2, 3]. Для достижения указанной цели законодатель предоставил ФНС России полномочия проверять достоверность сведений при регистрации компаний, а также определять основания, условия и способы такой проверки $[4,5]$.

В рамках статьи попытаемся осмыслить границы и объем полномочий регистрационного органа - ФНС России - по проверке достоверности адреса юридического лица, как обязательного элемента, включаемого в ЕГРЮЛ, акцентируя внимание на критериях, используемых судебной практикой при разрешении споров об отказах в регистрации юридических лиц в связи с недостоверностью адреса.

\section{Результаты}

Обращаясь к первой редакции Федерального закона от 08.08.2001 года № 129-Ф3 «О государственной регистрации юридических лиц и индивидуальных предпринимателей» (далее - Федеральный закон № 129-Ф3) мы видим, что оснований для отказа в регистрации юридического лица изначально было всего два - не полный пакет документов и подача их в ненадлежащий орган. Дебюрократизация в сфере регистрации юридических лиц была в целом положительно воспринята многими юристами, однако отсутствие даже формального легалитета записи в реестр, подвергалось критике, высказывались мнения о целесообразности предоставления регистрирующему органу полномочий по проведению минимально-необходимых проверочных мероприятий. Круг этих полномочий являлся дискуссионным вопросом, но цель предполагалась в обеспечении защищенности интересов как общества в целом, так и интересов отдельных субъектов предпринимательской деятельности [6, с.99-100]. Начавшееся в нулевые годы XXI века рейдерство, развитию которого отчасти способствовало законодательство, предписывающее либеральный порядок регистрационных процедур и освободившее регистрирующие органы от обязанности проверять законность, подлинность учредительных документов и достоверность содержащихся в них сведений, вызвало естественную реакцию государства, озаботившегося защитой экономических интересов и повлекло постепенное усложнение процедуры регистрации юридических лиц и индивидуальных предпринимателей, систематическое расширение основание для отказа в государственной регистрации (в настоящее время их 26), и, соответственно увеличение объема полномочий регистратора, в том числе и в части проверки сведений, содержащихся в предоставляемых на регистрацию документов.

Одним из полномочий регистратора по действующему законодательству является проверка достоверности адреса юридического лица. До недавнего времени наблюдалась терминологическая путаница в использовании понятий «юридическая адрес», «адрес юридического лица» и «местонахождение юридического лица». Отметим, ГК РФ, Федеральный закон № 129-Ф3 и ведомственные правовые акты ФНС понятием «юридический адрес» не оперируют, данный термин относится к разряду бытовых, общеупотребительных и юридической нагрузки не несет. Адрес юридического лица и место нахождения юридического лица не являются тождественными понятиями. Место нахождения - это наименование населенного пункта (муниципального образования), в границах которого находится постоянно действующий исполнительный орган юридического лица либо лицо, уполномоченное выступать от его имени и где осуществляется государственная регистрация. Адрес, как базовая идентификационная характеристика юридического лица, позволяющая осуществлять с ним двухстороннюю связь, указывается в ЕГРЮЛ в пределах места нахождения юридического лица, и должен содержать определённый Приказом ФНС России от 31.08.2020 № ЕД-7-14/617@ «Об утверждении форм и требований к оформлению документов, представляемых в регистрирующий орган при государственной регистрации юридических лиц, индивидуальных предпринимателей и крестьянских (фермерских) хозяйств» перечень адресообразующих элементов». Полномочия ФНС об утверждении форм и требований к регистрационным документам установлены Правительством РФ и зафиксированы в п.п. 5.9.38 и 5.9.39 Положения о Федеральной налоговой службе [7].

Регистрирующий орган требует заполнения соответствующих граф об адресе с использованием сведений из федеральной информационной адресной системой (ФИАС), оператором которой является ФНС. До 2011 года, когда ФИАС начала действовать на территории Российской Федерации, адреса по которым в учредительных документах зарегистрированы организации, адреса в КЛАДИР (ведомственный классификатор ФНС адресов России), адреса баз данных Почты России различались, поскольку единых требований установлено не было. В 2010 году был введен ГОСТ Р 53339-2009 «Данные пространственные базовые» и установлено понятие «удостоверение местоположения пространственного объекта как описание пространственного объекта с помощью набора данных, включающего в себя координатное описание, идентификатор, наименование (при наличии - адрес) объекта, описание его топологических отношений с другими пространственными объектами, предоставляемое юридически значимым источником пространственных данных». С 2018 года кодировки ФИАС стали обязательными к применению при работе адресной информацией при удостоверении местоположения пространственного объекта. В настоящее время ФИАС используется сотнями тысяч коммерческих ор- 
ганизаций РФ такими как DPD, СДЭК, Почта РФ, ozon.ru, банковской отраслью, включена в качестве эталонного адресного справочника в программные продукты «1С» и т.д.

Однако несмотря на десятилетний срок существования эксперты отмечают отсутствие значительно количества адресных сведений, несоответствие написания элементов адреса одних и тех же объектов в ФИАС и других юридически значимых источниках, к примеру, у учредителей юридического лица адреса регистрации в паспортах не соответствуют КЛАДРу и ФИАС: в паспорте - дом 9, а по КЛАДРу и ФИАС- домовладение 9, либо в паспорте - дом 49 (без букв, литер, корпусов и т.п.), по КЛАДРу и ФИАС - дом 49 литера А. Это порождает проблемы при осуществлении регистрационных действий, поскольку несоответствие адреса, указанного заявителем в типовых формах документов (например, при регистрации юридического лица по месту проживания учредителя) сведениям в ФАИС, регистрирующий орган расценивает как недостоверность сведений, что влечет принятие решения в отказе в регистрации. Полагаем, принятие подобных решений выходит за рамки полномочий регистрирующего органа, поскольку сам по себе факт отсутствия сведений в ФИАС не делает сведения об адресе недостоверными, а требует проведения проверочных мероприятий, обязанность проведения которых регистратором прямо установлена нормативными правовыми актам [4,5]. В судебной практике мы находим подтверждения данному походу. К примеру, в решении от 7 июля 2014 г. по делу № А40-62706/2014 Арбитражный суд г. Москвы указывает, что отсутствие адреса в ФИАС не свидетельствует о том, что по указанному адресу невозможно будет осуществить связь с юридическим лицом, а Пленум ВАС РФ в Постановлении от 30 июля 2013 г. № 61 «О некоторых вопросах практики рассмотрения споров, связанных с достоверностью адреса юридического лица» (далее - Пленум № 61) разъяснил, что отказ в государственной регистрации по мотиву недостоверности представленных сведений об адресе юридического лица возможен лишь при наличии подтвержденной информации, то есть о том, что такой адрес был указан без намерения использовать его для осуществления связи с юридическим лицом.

Бизнес-сообщество неоднократно отмечало, что у давно действующих предприятий, после инвентаризации данных в ФИАС, написание адреса изменилось и не совпадает со сведениями в ЕГРЮЛ, хотя фактически предприятия остаются на месте, а изменения связаны с технической стороной вопроса формализации и упорядочения адресных элементов. ФНС в этой ситуации направляет извещения о необходимости внести изменения в данные об адресе юридического лица в соответствии с положениями Федерального закона № 129-Ф3. Однако с учетом того, что инвентаризация и изменения адресной информации проводились по инициативе государственных органов, оператором Системы является ФНС, регулятором - Минфин России, а органами, уполномоченными на присвоение адресов объектам адресации - ОМСУ и органы государственной власти субъектов РФ - городов федерального значения, то решение проблемы, по нашему мнению, должно возлагаться не на предпринимателей, а на властных субъектов разрешительных отношений и носить административный формально-технический процедурный характер.

Другим аспектом проверки достоверности адреса юридического лица, проводимой в рамках полномочия ФНС России, является установление его массовости. Термин «адреса массовой регистрации» был введен в оборот приказом ФНС РФ от 29.12.2006 № САЭ-3-09/911@ «Об информационной поддержке», в дальнейшем критерий массовости был упомянут в Пленуме № 61 как обстоятельство, позволяющее считать сведения об адресе юридического лица недостоверным; и, в конечном итоге, был нормативно зафиксирован в приказе ФНС России от 11.02.2016 № МMB-7-14/72@ [4] как одно из оснований для проведения мероприятий по проверке достоверности сведений, включаемых в ЕГРЮЛ. Причем если Пленум № 61 трактует «адрес массовой регистрации» исходя из содержательного признака - как «адрес большого количества юридических лиц, в отношении всех или значительной части которых имеются сведения о том, что связь с ними по этому адресу невозможна», то в приказе ФНС России № ММВ-7-14/72@ для определения массовости использован формальный критерий - «указанный адрес в соответствии с содержащимися в ЕГРЮЛ сведениями является адресом пяти и более юридических лиц». Разница в подходах отражается в правоприменительной практике. ФНС ведет электронный сервис «Адреса, указанные при государственной регистрации в качестве места нахождения несколькими юридическими лицами» в котором ведет учет «массовых адресов», подпадающих под это определение по формальному признаку, если в отношении них не принято решений руководителя ФНС о невключении в реестр как массового. Регистрирующий орган, нередко, установив, что по адресу, указанному в заявлении о госрегистрации уже «прописано» 5 и более компаний формально подходит к вопросу и выносит отказ в регистрации по мотиву недостоверности сведений. Позиция судов при разрешении споров об отказе в регистрации при данных обстоятельствах основывается на том, что ключевой критерий недостоверности адреса - невозможность устойчивой связи с юридическим лицом. Поэтому суды расценивают как отсутствие намерения осуществлять деятельность по адресу регистрации по указанному адресу, в частности, следующие обстоятельства:

- буквенная нумерация офиса носит временный характер и указывается формально; 
- в отношении ранее зарегистрированных по рассматриваемому адресу юридических лиц принято решение о ликвидации в связи с невозможностью установить связь с юридическим лицом, или имеется отметка о недостоверности адреса;

- незначительная площадь помещения, в котором зарегистрированы несколько юридических лиц [8].

С другой стороны, суды полагают достоверным адрес при условии, что [9]:

- спорный адрес не числится в ЕГРЮЛ как «массовый» адрес;

- по рассматриваемому адресу зарегистрированы как «проблемные», так и «непроблемные» юридические лица, связь с которыми осуществляется;

- офисное помещение обладает достаточной площадью, чтобы при наличии других организаций иметь возможность территориального размещения, пусть даже и за одним столом

Необходимо отметить, что полномочия ФНС по проверке достоверности адреса юридического лица при создании такового ограничены лишь одним способом - изучением документов и сведений, имеющихся у регистрирующего органа, в том числе возражений заинтересованных лиц, а также документов и пояснений, представленных заявителем (пп. "а" п. 4.2 ст. 9 Федерального закона №129-Ф3, п. 8 Приказа ФНС России от 11.02.2016 N MMB-7-14/72@), однако указанное ограничение не действует при совершении иных регистрационных действий, где допустимо применение всех способов, указанных в п. 4.2. ст. 9 Федерального закона №129-Ф3. Касательно документов и пояснений, представленных заявителем, Федеральный закон №129-Ф3 и Пленум № 61 четко указывает, что это право, но не обязанность заявителя, в отношении полномочий регистрирующего органа четко сформулирован запрет на: (1) требовать предоставления каких-либо документов, свыше предусмотренных в качестве обязательных законом; (2) возлагать бремя доказывания достоверности сведений на заявителя. С другой стороны, Пленум № 61 разъяснят, что, к примеру, регистрация юридического лица по месту жительства его учредителя (директора) возможно при наличии согласия собственника. В действующих нормативных правовых актах нет разъяснений, как быть в том случае, если квартира находится в ипотеке или является муниципальным жильем (директор проживает в ней на основе договора социального найма), нет прямого указания на обязанность регистрирующего органа самостоятельно затребовать документ, подтверждающий согласие собственника или иные документы. Практика складывается таким образом, что для успешного и быстрого прохождения регистрационных процедур заявитель вынуждены предоставлять гарантийные пись- ма, согласия собственника объекта недвижимости, документы, подтверждающие право собственности, и.т. На профессиональных форумах даже описывается практика подтверждения достоверности адреса на американский манер - кроме договора к пакту регистрационных документов прикладывают конверт заранее отправленного и полученного заказного письма, и фотографии офиса. Регистрирующий орган не наделен полномочиями по юридической оценке представленных документов, в частности, не вправе проводить юридический анализ договора аренды офисного помещения, либо гарантийного письма.

Судебная практика не считает гарантийные письма и иные документы сверх необходимого, установленного законодательно комплекта, необходимым и достаточным подтверждением достоверности сведений об адресе юридического лица, оценивая их наличие (отсутствие) в совокупности с другими представленными доказательствами [8,9], ориентируя регистрирующие органы на использование предоставленных им полномочий по проверке и возможности межведомственного взаимодействия максимально широко, без фактического вынуждения заявителя к самостоятельному сбору доказательств, подтверждающих достоверность адреса юридического лица.

Заключение. Проведенный анализ показывает, что нормативные положения, регламентирующие деятельность ФНС по регистрации юридических лиц, с одной стороны системно увеличивают объем полномочий регистратора, в том числе и в части проверки сведений, содержащихся в предоставляемых на регистрацию документов, а с другой предпринимают попытки к максимально возможному уменьшению фактора субъективизма оценки при принятии решения о государственной регистрации либо отказе в таковой.

Нормативные положения, регламентирующие деятельность ФНС по регистрации юридических лиц в части проверки достоверности сведений, нуждаются в уточнении и корректировке как на законодательном уровне, так и в рамках ведомственных нормативных документов. Полагаем в настоящий момент необходимым: (1) на законодательном уровне нормативное закрепление процедуры установления соответствий (наличия) фактического адреса и адреса в ФИАС в случаях, носящий чисто технический характер, без предъявления требований к юридическому лицу о прохождении регистрационных и иных процедур; (2) на ведомственном уровне - разработка методических рекомендаций, содержащих чёткий алгоритм действий по проверке достоверности сведений при регистрации юридического лица на основе практики обжалования решений об отказе в регистрации в ФНС и судебном порядке. 


\section{ЛИТЕРАТУРА}

1. Безвенко Р.С. Торговая регистрация и торговые реестры: история и теория // Вестник экономического правосудия РФ. 2019. № 6. С. 68-91.

2. Публичная декларация целей и задач ФНС России на 2020 год // Официальный сайт ФHC России. URL: https://www.nalog.ru/rn77/news/activities_ $\mathrm{fts} / 9754334 /$

3. Об утверждении Стратегической карты ФНС России на 2017 - 2021 годы: [приказ ФНС России от 02.12.2016 N MМВ-7-1/666@] // Доступ из СПС «Консультант Плюс». URL: http://www.consultant.ru/document/cons_doc_LAW_255179/

4. Об утверждении оснований, условий и способов проведения указанных в пункте 4.2 статьи 9 Федерального закона «0 государственной регистрации юридических лиц и индивидуальных предпринимателей» мероприятий, порядка использования результатов этих мероприятий, формы письменного возражения относительно предстоящей государственной регистрации изменений устава юридического лица или предстоящего внесения сведений в Единый государственный реестр юридических лиц, формы заявления физического лица о недостоверности сведений о нем в Едином государственном реестре юридических лиц: [приказ ФНС России от 11.02.2016 № MMB-7-14/72@] // 0фициальный сайт ФHC России. URL: https://www.nalog.ru/rn77/ about_fts/docs/6085364/

5. О государственной регистрации юридических лиц и индивидуальных предпринимателей: [федер. закон № 129-Ф3: принят Гос. Думой 13 июля 2001; ред. от 26.11.2019] // Официальный интернет-портал правовой информации. URL: http://pravo.gov.ru/proxy/ips/?docbody=\&nd=102072405

6. Габов А.В. Эволюция регистрационной системы создания юридических лиц в России: основные этапы и тенденции // Учен. зап. Казан. ун-та. Сер. Гуманит. науки. 2019. №4. С.77-126.

7. Об утверждении Положения о Федеральной налоговой службе: [постановление Правительства РФ от 30.09.2004 № 506; ред. от 30.11.2019] // 0фициальный интернет-портал правовой информации. URL: http://pravo.gov.ru/proxy/ips/?docbody=\&nd=102088804\&intelsearch=\%EE\%F2+30.09.2004+\%B9+506

8. Постановление от 21 января 2020 г. по делу № A45-8810/2019. Арбитражный суд Западно-Сибирского округа: [Электронный ресурс]. URL: https: //sudact. ru/arbitral/doc/ffaStbF8VRVL/

9. Решение от 14 ноября 2018 г. по делу № A42-8147/2018. Арбитражный суд Мурманской области: [Электронный ресурc]. URL: https://sudact.ru/arbitral/ doc/7MwmKDd7fzmH/

(с) Кузнецов Павел Александрович (tvinco@mail.ru).

Журнал «Современная наука: актуальные проблемы теории и практики»

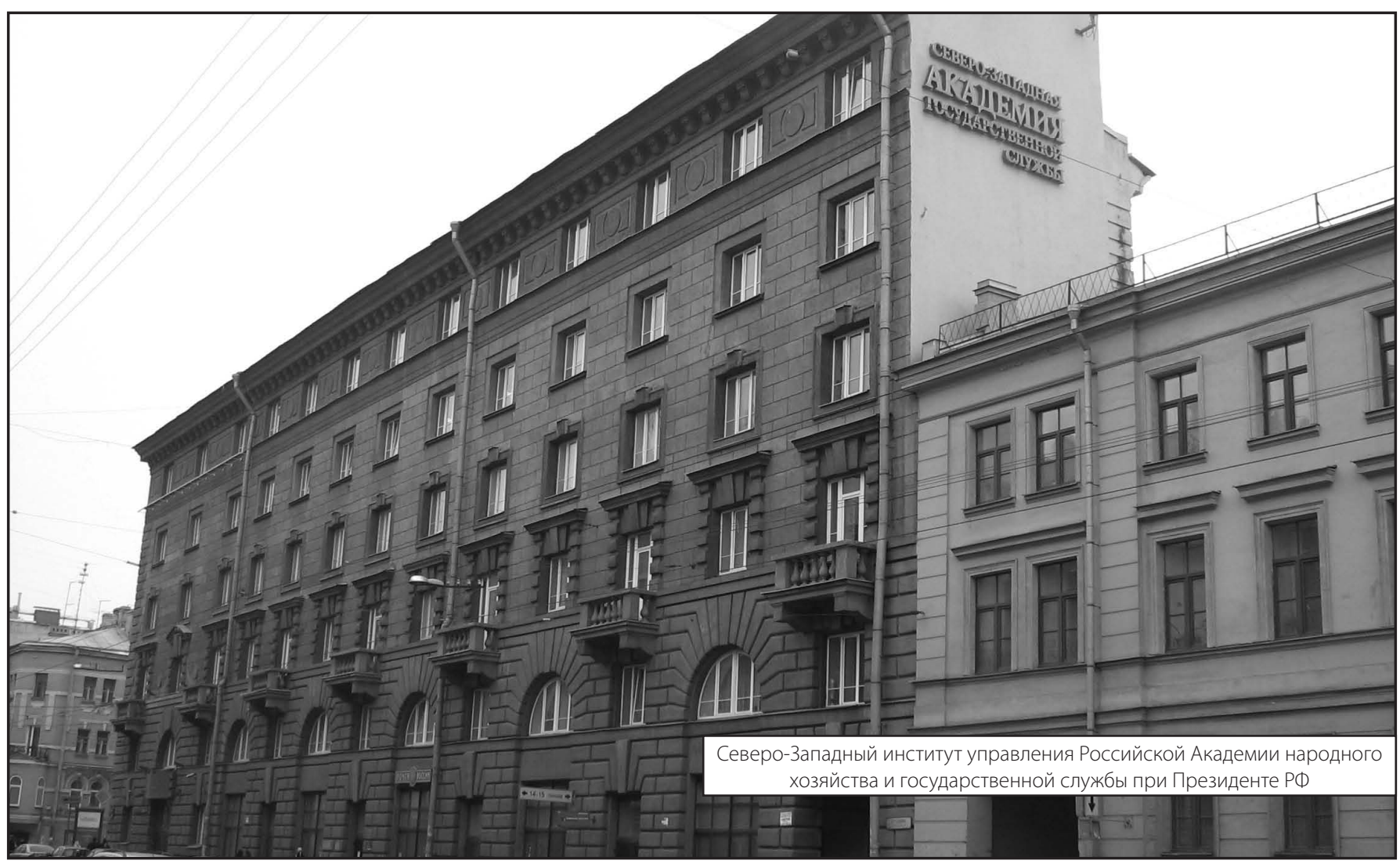

